Marquette University

e-Publications@Marquette

Economics Faculty Research and Publications

Business Administration, College of

$12-1-2006$

\title{
Openness, the Sacrifice Ratio, and Inflation: Is There a Puzzle?
}

Joseph P. Daniels

Marquette University, joseph.daniels@marquette.edu

David D. VanHoose

Baylor University

Accepted version. Journal of International Money and Finance, Vol. 25, No. 8 (December 2006): 1336-1347. DOI. Published under Creative Commons license Attribution-NonCommercialNoDerivatives 4.0 International. 


\title{
Openness, the sacrifice ratio, and inflation: Is there a puzzle?
}

\author{
Authors: Joseph P. Daniels ${ }^{\mathrm{a}, \star}$, David D. VanHoose ${ }^{\mathrm{b}, 1}$
}

\begin{abstract}
The standard time-inconsistency-based explanation for the negative correlation between openness and inflation requires an inverse relationship between the sacrifice ratio and openness, but Daniels et al. (2005, Openness, central bank independence, and the sacrifice ratio. Journal of Money, Credit, and Banking 37 (2), 371-379.) have provided evidence that controlling for central bank independence reveals a positive relationship. This paper embeds the time-inconsistency approach within a model of a multisector, imperfectly competitive, open economy. In this setting, greater openness raises the sacrifice ratio but reduces the inflation bias. Thus, failure to observe an inverse relationship between openness and the sacrifice ratio does not necessarily imply that the time-inconsistency approach is irrelevant to understanding the openness-inflation relationship.
\end{abstract}

\section{Introduction}

Traditional explanations concerning the documented inverse relationship between openness and trend inflation rely on the idea that increased openness worsens the terms of the output-inflation trade-off and thereby reduces the incentive for a monetary authority to engage in discretionary policies that boost the mean inflation rate. Romer (1993) argues that greater openness effectively steepens the Phillips curve by exposing a nation to a larger negative terms-of-trade effect generated by an expansion of domestic output. This explanation arguably applies mainly to nations sufficiently large to influence international relative prices, so Lane (1997) focuses on how greater openness reduces the potential output gains from unexpected inflation in non-traded-goods sectors with imperfectly competitive goods markets and sticky prices.

Nevertheless, Temple's (2002) cross-country analysis of sacrifice ratios-ratios of the national output losses to corresponding reductions in inflation rates (see Ball, 1994 )-provides meager support for the view that a worsened output-inflation trade-off accounts for the inverse relationship between openness and inflation. This has led Temple to suggest that it may be appropriate to consider rejecting the time-inconsistency approach as an explanation for the openness-inflation relationship. He specifically suggests considering an alternative framework that emphasizes inflation's role in influencing the costs that exchange-rate volatility imposes in more open economies.

1 Daniels \& VanHoose 
While his suggestion certainly is an avenue worthy of further exploration, recent work by Gruben and McLeod $(2002,2004)$ indicates that the time-inconsistency approach remains a potentially fruitful explanation of the openness-inflation relationship. Whereas Gruben and McLeod suggest that greater capital-markets openness may act as a policy commitment mechanism that yields lower average inflation, in this paper we follow Lane (1997) and, more broadly, the new open economy macroeconomics literature [see, for instance, Sarno, 2000, 2001; Obstfeld, 2001; Lane, 2001; VanHoose, 2004] by emphasizing real-sector factors influencing central bank incentives.

Specifically, we examine a model in which imperfect competition and incomplete wage rigidity are important characteristics of open economies. We incorporate the assumptions of economy-wide monopolistic competition and partial nominal wage contracting into a textbook one-shot-policy-game framework that allows us to examine essential features of the openness inflation relationship. In contrast to Lane (1997), all sectors of the economy in our model are populated with monopolistically competitive firms that sell imperfectly substitutable products to both domestic and foreign consumers. Our use of this model allows us to demonstrate that the time-inconsistency/discretionary-policy approach can be fully consistent with both (1) a shallower output-inflation trade-off (that is, a larger sacrifice ratio, as suggested by empirical evidence recently provided by Daniels et al., 2005) and (2) a negative relationship between the degree of openness and trend inflation. Thus, failure to find that greater openness steepens the output-inflation trade-off in cross-country data is not sufficient grounds for abandoning the timeinconsistency theory as a basis for understanding the determinants of the openness-inflation relationship. A positive correlation between the openness and the sacrifice ratio even in the presence of an inverse relationship between openness and mean inflation is consistent with the results of our analysis.

This conclusion rests on the following line of reasoning. In the standard Barro-Gordon (1983) approach, a shallower output-inflation trade-off provides a greater incentive to engage in unanticipated monetary expansions, so that the essential basis for explaining the opennessinflation relationship is, as emphasized by Temple, the effect of openness on the shape of the output-inflation trade-off. The standard Barro-Gordon framework, however, is based on the assumptions of pure competition and economy-wide nominal wage contracts, so the shape of the output-inflation trade-off ultimately depends on the shape of the aggregate supply function. In imperfectly competitive economies, however, firms set prices, so there is no aggregate supply curve. Furthermore, when only a portion of firms in the economy use nominal wage contracts, 
variations in the extent of nominal wage rigidity in the economy affect the channels through which openness influences macroeconomic variables. As a consequence, under imperfect competition and incomplete wage rigidity there is a broadening of the factors that can affect the nature of the output-inflation trade-off. Included among these factors are the interplay among the share of firms with wage contracts, the substitutability of products, the real-exchange-rate sensitivity of aggregate expenditures, and the degree of openness to international trade. These factors together influence the pricing power available to firms and, therefore, the response of inflation to changes in aggregate demand induced by monetary policy actions.

In the framework examined in this paper, increased openness contributes to reduced pricing power of domestic firms. Hence, in an economy characterized by monopolistic competition, there is a shallower output-inflation trade-off, so that the sacrifice ratio increases when the economy becomes more open. At the same time, however, the reduction in firms' pricing power induced by greater openness hampers the extent to which of any given monetary expansion can boost output by producing unexpected price increases. As a consequence, even though greater openness increases the sacrifice ratio, it also has the effect of reducing the trend inflation rate arising from discretionary monetary policy.

Our analysis thereby indicates that relationships predicted by the standard timeinconsistency approach will not apply to nations with economic structures that fail to satisfy its background assumptions of pure competition and economy-wide nominal contracting. This implies that it may be problematical to draw inferences about the policy implications of openness using cross-country data or from data pooled from a number of nations without controlling for structural differences across countries. For instance, for nations in which imperfect competition and mixed labor-market structures predominate, the time-inconsistency theory may explain the openness-inflation relationship even if greater openness is associated with a higher sacrifice ratio. In other nations with structures that more closely match the background assumptions adopted by Romer (economy-wide pure competition, nominal wage rigidities, and sufficient size to affect international relative prices) or Lane (perfectly substitutable tradable goods but non-tradable goods sold in imperfectly competitive domestic markets with sticky prices), the standard argument implying a lower sacrifice ratio would still apply. Across a set of nations with mixed goods-market and labor-market structures, therefore, mixed empirical results such as those obtained by Temple would not necessarily be surprising, nor particularly puzzling.

To demonstrate these points, we develop a model that imbeds the basic Barro-Gordon

\section{Daniels \& VanHoose}


discretionary-policy model imbedding imperfect competition as a key factor governing the interplay among the economies of nations open to trade. We use a stylized framework that in some respects is similar to the theoretical model developed by Karras (1999) in his panel study of the relationship between openness and the effects of monetary policy on inflation and output using data pooled from 38 countries. Our work is also analogous to earlier contributions by Rogoff (1985), Hardouvelis (1992), and Rasmussen (1993) that have addressed the effects of international trade and exchange rate regimes on discretionary monetary policy choices. In contrast to these earlier contributions, however, in our open economy framework firms are monopolistically competitive, and only a portion of firms use wage contracts.

Section 2 presents our model of an open economy containing monopolistically competitive firms. Section 3 evaluates how changes in the extent of product substitutability and the degree of openness jointly influence the output-inflation trade-off. In this section, we demonstrate that a greater degree of product-market substitution and increased openness have self-reinforcing effects that tend to increase the sacrifice ratio in an economy characterized by monopolistic competition. In Section 4, we show that within such an economy, greater product substitutability and increased openness nonetheless contribute to a decreased incentive for a discretionary monetary authority to engage in inflationary monetary policies. Section 5 summarizes our conclusions.

\section{An open, multisector economy with monopolistic competition}

The theoretical framework incorporating monopolistic competition among atomistic firms within a multi sector economy builds on the model developed in Duca and VanHoose (2000). There are many sectors in the economy, indexed $i$, which are distributed uniformly along a unit interval. Each sector contains large numbers of workers and firms. Identical firms within a sector produce an identical good. This good is differentiated from the goods produced by firms in other sectors. Following the earlier work of Ball (1988) and Duca and VanHoose, we assume for the sake of both expositional simplicity and analytical tractability that the price elasticity of demand is the same across sectors. Thus, goods are equally differentiated throughout the economy.

A fraction, $\Omega$, of sectors contain workers and firms that use contracts to set nominal wages in advance of labor-market clearing. Spot labor markets determine their nominal wages in the remaining portion of sectors, $1-\Omega$. In a closed-economy version of this basic framework, Duca and VanHoose (2001) show that if risk-neutral firms and risk-averse workers face common aggregate shocks and heterogeneously distributed sector-specific disturbances, the 
contract share of sectors, $\Omega$, typically lies between zero and unity but declines as the variability of sector-specific disturbances increases relative to the volatility of aggregate shocks. To maintain tractability, we abstract from considerations of disturbances that influence the endogenous determination of the contract share. Hence, we treat the contract share as an exogenous parameter.

The output produced by a given firm in sector $i$ is given by

$$
y_{i}=\alpha l_{i}
$$

where $y_{i}$ is the $\log$ of output and $l_{i}$ is the $\log$ of employment at firm $i$. We could include a productivity shock, but it would not influence trend inflation in the standard Barro-Gordon (1983) discretionary-policy framework. We simplify, therefore, by assuming that any potential supplyand demand-side disturbances always equal zero ex post, hence we exclude explicit consideration of such shocks from the analysis. The demand for the output of a domestic firm in sector $i$ as a share of aggregate domestic output is

$$
y_{i}-y=-\varepsilon\left(p_{i}-p\right)
$$

where $y \equiv \int_{0}^{1} y_{i} \mathrm{~d} i$ is the log of aggregate domestic output, $p \equiv \int_{0}^{1} p_{i} \mathrm{~d} i$ is the log of the aggregate domestic price level, and $\varepsilon>1$ is the elasticity of demand for the output of firms in sector $i$ of the domestic country.

The domestic nation's income-expenditure equilibrium condition (for a derivation of this Cobb-Douglas approximation, see, for instance, Canzoneri and Henderson, 1991; or Bryson et al., 1993) is given by

$$
y=\eta\left(p^{*}+s-p\right)+(1-\beta) y+\beta^{*} y^{*}
$$

where the home and foreign propensities to import, $\beta$ and $\beta^{*}$, are fractions; $\eta$ is the elasticity of desired spending with respect to the real exchange rate; $p^{*}$ is the log of the aggregate foreign price level; $s$ is the log of the foreign currency price of domestic currency; and $y^{*}$ is the log of aggregate foreign output.

Domestic income is determined by the quantity equation,

$$
y=m-p
$$


where we simplify by normalizing velocity at unity, so that the log of velocity equals zero.

Taking antilogs of Eqs. (1)-(4) and combining the resulting expressions with the profit function, $\pi_{i}=P_{i} Y_{i}-W_{i} L_{i}$, yields the labor demand function for a firm in sector $i$ (with the intercept suppressed because it plays no role in our subsequent analysis):

$$
l_{i}^{\mathrm{d}}=\frac{-\varepsilon\left(w_{i}-p\right)+\eta\left(p^{*}+s-p\right)+(1-\beta)(m-p)+\beta^{*} y^{*}}{\alpha+\varepsilon-\alpha \varepsilon},
$$

where $w_{i}$ is the $\log$ of the nominal wage at a firm in sector $i$, which we assume faces a perfectly competitive labor market.

As in Ball (1988), within each sector the numerous firms face a pool of immobile workers. Workers can consume both domestically produced output and foreign-produced goods. Consequently, labor supply depends on the real wage computed in terms of the overall price workers pay for a basket of both domestic and foreign goods:

$$
l_{i}^{s}=\lambda\left[w_{i}-(1-\beta) p-\beta\left(p^{*}+s\right)\right]
$$

where $\lambda>0$. For sectors with or without nominal wage contracts, the full-information, marketclearing wage satisfies Eqs. (5) and (6) simultaneously and equals

$$
\begin{gathered}
\left(w_{-} i\right)^{\wedge}=\left\{[\lambda(\alpha+\varepsilon-\alpha \epsilon)(1-\beta)+\varepsilon] p+\lambda(\alpha+\varepsilon-\alpha \varepsilon) \beta\left(p^{\wedge} *+s\right)+\eta\left(p^{\wedge} *+s-\right.\right. \\
\left.p)+(1-\beta)(m-p)+\beta^{\wedge} * y^{\wedge} *\right\} /\{[\lambda(\alpha+\varepsilon-\alpha \varepsilon)+\varepsilon]\} .
\end{gathered}
$$

This is the wage actually paid by a firm in sector $i$ if its sector is among the share, $1-\Omega$, of sectors that do not use contracts.

Specifying analogous structural relationships for a foreign nation would yield a twocountry framework in which $y^{*}$ and $p^{*}$ would be endogenous variables. In this paper, however, we assume the output and prices abroad are exogenously determined. Henceforth we simplify the exposition by assuming that the foreign money stock, foreign price level, and foreign output equal unity, so that $m^{*}, p^{*}$, and $y^{*}$ equal zero.

Substitution of Eq. (7) into either Eq. (5) or Eq. (6) and the result into Eq. (1) yields the output of a noncontract (nc) firm:

$$
y_{i}^{\mathrm{nc}}=\alpha \lambda\left(\frac{(\eta-\beta \varepsilon)(s-p)(1-\beta)(m-p)}{[\lambda(\alpha+\varepsilon-\alpha \varepsilon)+\varepsilon]}\right) .
$$

\section{Daniels \& VanHoose}


At a contract firm, nominal wage contracts are set to satisfy $w_{i}^{\mathrm{c}}=\widehat{w_{i}^{* e}}$, where the superscript $e$ denotes the conditional expectation of a variable given information available in the previous period. Substituting the result of Eq. (7) into Eq. (5) and Eq. (1) yields the output a firm in a sector with a wage contract:

$$
\begin{aligned}
y_{-} i^{\wedge} \mathrm{c}= & \left\{\alpha \left\{\varepsilon[\lambda(\alpha+\varepsilon-\alpha \varepsilon)+\varepsilon]\left(p-p^{\wedge} \mathrm{e}\right)+[\lambda(\alpha+\varepsilon-\alpha \varepsilon)+\varepsilon] \times(1-\beta)(m-p)-\right.\right. \\
& \left.\left.(1-\beta) \varepsilon\left(m^{\wedge} \mathrm{e}-p^{\wedge} \mathrm{e}\right)+\eta[\lambda(\alpha+\varepsilon-\alpha \varepsilon)+\varepsilon] \times(s-p)\right\}\right\} /\{[\lambda(\alpha+\varepsilon-\alpha \varepsilon)+ \\
& \varepsilon](\alpha+\varepsilon-\alpha \varepsilon)\} .
\end{aligned}
$$

Output of contracting firms, therefore, responds to unexpected price-level changes.

In Eqs. (8) and (9), the parameter $\eta$, which measures the sensitivity of expenditures on domestic output in response to a change in the real exchange rate, naturally influences the responsiveness of sectoral outputs to real-exchange-rate variations. The domestic propensity to import, $\beta$, more broadly governs how sectoral outputs respond to both real-exchange-rate variations and changes in domestic real money balances. This is so because the magnitude of $\beta$ plays two important roles in the model. First, together with the magnitude of $\eta$, the propensity to import determines the relative importance of real-exchange-rate effects versus income effects on total spending on domestic output. Second, the size of $\beta$ determines the relative importance of domestic prices and exchange-rate-adjusted foreign prices in the domestic consumer price index, given by $(1-\beta) p+\beta\left(p^{*}+s\right)$, where $1-\beta$ is the weight on expenditures on domestic goods and $\beta$ is the weight on expenditures on foreign goods.

\section{Openness and the sacrifice ratio}

Because firms behave identically within each sector, $y_{i}^{\mathrm{c}}=y^{\mathrm{c}}$ for all $i \epsilon[0, \Omega]$ and $y_{i}^{\mathrm{nc}}=y^{\mathrm{nc}}$ for alli $\epsilon(\Omega, 1]$. It follows that $y=\Omega y^{\mathrm{c}}+(1-\Omega) y^{\mathrm{nc}}$. Substituting Eqs. (8) and (9) into this expression and differentiating with respect to the aggregate price level, holding all other variables unchanged, yields

$$
\frac{\partial y}{\partial p}=\frac{\Omega \alpha \varepsilon[(\varepsilon-\eta)-(1-\beta)]+\alpha \lambda(\alpha+\varepsilon-\alpha \varepsilon)[(\beta \varepsilon-\eta)-(1-\beta)(1-\varepsilon \Omega)]}{[\lambda(\alpha+\varepsilon-\alpha \varepsilon)+\varepsilon](\alpha+\varepsilon-\alpha \varepsilon)} .
$$

This price sensitivity expression governs the short-run output-inflation trade-off. In standard Barro-Gordon-style models, the output-inflation trade-off naturally arises as the slope of an aggregate supply curve constructed by aggregating over the output supply curves of price7 Daniels \& VanHoose 
taking, perfectly competitive firms. Under imperfect competition, of course, there are no firmlevel supply curves, so there is no aggregate supply curve. The expression in Eq. (10), therefore, is the slope of the relationship between the aggregate output produced by profit-maximizing, price-setting firms and the overall level of prices they set. A standard positive slope emerges for this relationship as long as $\varepsilon$ and $\beta$ are sufficiently large (that is, the extent of domestic competition and the degree of openness are sufficiently large) in relation to $\eta$ (the sensitivity of desired spending on domestic output relative to the real exchange rate). Thus, given a value of $\eta$, the output-inflation trade-off is more likely to be positively sloped in an economy that is relatively open and in which there is a reasonably large extent of rivalry among imperfectly competitive firms.

The standard measure of openness found in the literature is the nation's propensity to import, $\beta$, which Temple (2002) and others have used to evaluate the effects of openness on the sacrifice ratio, under the assumption that the sacrifice ratio captures the terms of the outputinflation relationship governed by the slope of an aggregate supply schedule. Here, of course, the output-inflation relationship arises from the aggregate responses of aggregate output across price-setting firms given changes in their aggregate profit-maximizing prices. To determine how an increase in $\beta$ affects the output-inflation relationship, therefore, we differentiate Eq. (10) with respect to $\beta$ to obtain

$$
\frac{\partial(\partial y / \partial p)}{\partial \beta}=\frac{\alpha\{\varepsilon \Omega+\lambda(\alpha+\varepsilon-\alpha \varepsilon)[1+\varepsilon(1-\Omega)]\}}{[\lambda(\alpha+\varepsilon-\alpha \varepsilon)+\varepsilon](\alpha+\varepsilon-\alpha \varepsilon)}>0
$$

Thus, in our imperfectly competitive setting, an increase in the propensity to import unambiguously increases the responsiveness of aggregate output to a change in the price level. The reason is that greater openness makes desired spending on domestic output less sensitive to changes in domestic income. As a result, each firm's profit-maximizing price is less responsive to a change in aggregate domestic output. The aggregate price level is thereby less sensitive to aggregate output changes, implying an increased sensitivity of output to a change in the domestic price level. Thus, the model implies that greater openness improves the terms of the output-inflation trade-off, thereby at least modestly increasing a measured sacrifice ratio for this imperfectly competitive, multi sector, open economy.

The real-exchange-rate elasticity also affects aggregate output through labor demand and desired expenditures, as shown in Eqs. (3) and (5). Differentiating Eq. (10) with respect to $\eta$ implies

8 Daniels \& VanHoose 


$$
\frac{\partial(\partial y / \partial p)}{\partial \eta}=\frac{-\alpha[\Omega \varepsilon+\lambda(\alpha+\varepsilon-\alpha \varepsilon)]}{[\lambda(\alpha+\varepsilon-\alpha \varepsilon)+\varepsilon](\alpha+\varepsilon-\alpha \varepsilon)}<0
$$

A larger value of $\eta$ indicates a reduction in the interdependency of the domestic and foreign economies, moving the domestic nation toward a small open economy environment. Hence, greater interdependence-lower values of $\eta$-makes output more sensitive to a change in the price level, thereby yielding a higher sacrifice ratio. Moving to a small open economy environmentgreater values of $\eta$-implies a reduced responsiveness of output to price-level variations and, consequently, a lower sacrifice ratio.

The extent of nominal wage rigidity in the economy also affects the output-inflation tradeoff. Differentiating Eq. (10) with respect to $\Omega$ yields

$$
\frac{\partial(\partial y / \partial p)}{\partial \Omega}=\frac{\varepsilon \alpha[\varepsilon-\eta-(1-\beta)]+\alpha \lambda \varepsilon(1-\beta)(\alpha+\varepsilon-\alpha \varepsilon)}{[\lambda(\alpha+\varepsilon-\alpha \varepsilon)+\varepsilon](\alpha+\varepsilon-\alpha \varepsilon)}
$$

Because $0<\beta<1$ and $\varepsilon>1$, this expression is positive unless $\eta$ is sufficiently large. Wage rigidities in contract sectors affect the aggregate price level and thereby the pricing and production decision of firms in noncontracting sectors. In an interdependent economy in which $\eta$ is relatively small, an increase in the economy-wide extent of wage contracting, as reflected in a larger value of $\Omega$, raises the sensitivity of aggregate output to price-level variations. Thus, for most parameter configurations an increase in the extent of wage contracting raises the sacrifice ratio. As the model approaches the limiting case of a small open economy (that is, as $\eta$ rises toward ever-larger values), however, this effect is offset as terms-of-trade variations replace movements in the domestic price level as the predominant factor influencing domestic spending and, hence, aggregate output.

Finally, differentiating Eq. (10) with respect to $\varepsilon$ indicates, in a lengthy expression that we do not report here, that an increase in domestic competition increases the responsiveness of aggregate output to changes in the price level. Greater substitutability across the products of the imperfectly competitive firms reduces the pricing power available to each firm. For any given change in the quantity of output demanded, each firm has less scope for varying its price, so that the aggregate price level varies less in relation to any given change in output. Conversely, a given change in output is associated with a smaller change in the price level, so that the

\section{Daniels \& VanHoose}


measured sacrifice ratio tends to increase.

\section{Openness and optimal monetary policy}

In the basic Barro-Gordon model of discretionary monetary policymaking in the presence of nominal rigidities, the operating assumption of perfect competition and a singlesector economy implies a standard aggregate supply relationship. Embedding this framework into an open economy setting thereby implies that greater openness can be associated with lower mean inflation only if increased openness steepens the economy's output-inflation trade-off and thereby reduces the sacrifice ratio. This gives rise to the "puzzle" identified by Temple: Empirical evidence indicates that while greater openness across countries is associated with lower mean inflation rates, measured sacrifice ratios are not necessarily inversely related to openness.

In our multisector-model environment with economy-wide monopolistic competition, however, the relationship between aggregate output and the price level is no longer the standard aggregate supply curve. Instead, it is a relationship between the total output of imperfectly competitive firms and the aggregate level of prices that firms individually set in light of the level of openness, the extent to which firms in the economy use wage contracts, the degree of substitutability of domestic products, and the sensitivity of domestic spending to changes in the real exchange rate. As shown above, increased openness reduces the responsiveness of domestic spending to changes in domestic income. This induces smaller price changes by domestic firms in response to a given variation in output, which implies a shallower output-inflation trade-off. Thus, an analysis of inflation and openness in an economy such as the one we have examined would be predicted to reveal a direct relationship between openness and the sacrifice ratio. Indeed, this is consistent with empirical evidence offered by Daniels et al. (2005), who demonstrate that once one controls for the degree of central bank independence, a positive relationship between openness and the sacrifice ratio emerges from the same cross-country data considered by Temple (2002).

Even though our analysis indicates that greater openness improves the terms of the output-inflation trade-off, it also implies that increased openness should affect the incentive that the nation's central bank has to attempt to boost output via unexpected inflation. Specifically, because greater openness reduces the responsiveness of firms' prices to a given change in domestic output, it makes the price level less sensitive to monetary expansions. A given expansion in the money stock, therefore, will induce less inflation and 
provide a smaller boost in real output. This, in turn, reduces the central bank's incentive to try to engage in surprise inflations. In an imperfectly competitive multisector economy, therefore, it should be the case that greater openness is associated with a lower trend inflation rate.

To show that this is in fact the case, we consider a central bank that aims to minimize the policy loss function,

$$
L=E\left[(y-\hat{y}-K)^{2}+b \psi^{2}\right]
$$

In this loss function, $\hat{y}$ is full-information economy-wide output, which equals zero, and $K$ is an output distortion, As in Canzoneri and Henderson (1991) and numerous other openeconomy versions of Barro-Gordon-style frameworks, since the propensity to import determines the share of domestic income spent on home goods, it is also serves as the weight on the consumer price index, so $\psi \equiv(1-\beta) p+\beta s$ is consumer price inflation under our assumption that $p^{*}=0$ and with the additional simplifying assumption that $p_{-1}=s_{-1}=0$. For $K=0$, a zero-inflation policy minimizes the central bank's loss. In general, however, $K>0$, and because agents make ex ante choices without complete information, a zeroinflation monetary policy is time-inconsistent. In many versions of this Barro-Gordon framework, a common assumption is that the inflation rate is a choice variable for the central bank. In this model, however, the central bank determines the money stock. The equilibrium inflation rate then adjusts endogenously as imperfectly competitive firms alter their product prices.

In a setting with a floating exchange rate, the central bank minimizes Eq. (11) with respect to $m$, taking agents' expectations of the money stock, price level, and exchange rate as given. Using Eqs. (8), (9), and the expression for aggregate output, $y=\Omega y^{\mathrm{c}}+(1-\Omega) y^{\mathrm{nc}}$, together with Eqs. (3) and (4) yields two equations that can be solved for the ex ante equilibrium domestic price level and exchange rate, expressed in terms of the expected price level, expected exchange rate, and expected money stock. Together these price level and exchangerate solutions imply that the ex ante value of-the consumer price index is

$\psi=\frac{\left\{\left(\eta \gamma+\alpha \beta^{2} \varepsilon \Omega\right)(\gamma \lambda+\varepsilon)-\alpha \eta(\varepsilon \Omega+\gamma \lambda)+\alpha \varepsilon \beta^{2} \gamma \lambda(1-\Omega)\right\} m}{\eta(\gamma+\alpha \varepsilon \Omega)(\gamma \lambda+\varepsilon)+\left[\varepsilon \beta^{2} \gamma \lambda(1-\Omega)-\eta(\varepsilon \Omega+\gamma \lambda)\right]}+\frac{\left(n-\beta^{2}\right) \Omega \alpha \varepsilon\left\{(1-\beta) m^{\mathrm{e}}+[\gamma \lambda+\varepsilon-(1-\beta)] p^{\mathrm{e}}\right\}}{\eta(\gamma+\alpha \varepsilon \Omega)(\gamma \lambda+\varepsilon)+\left[\varepsilon \beta^{2} \gamma \lambda(1-\Omega)-\eta(\varepsilon \Omega+\gamma \lambda)\right]^{\prime}}$

where $\gamma \equiv \alpha+\varepsilon-\alpha \varepsilon$.

Substituting Eq. (12) and the expression for aggregate output into Eq. (11) and 11 Daniels \& VanHoose 
differentiating with respect to $m$, given $m^{\mathrm{e}}, p^{\mathrm{e}}$, and $s^{\mathrm{e}}$, yields the first-order condition for optimal monetary policy. Under rational expectations and in the presumed absence of disturbances, it must be true ex post that $m^{\mathrm{e}}=m=p^{\mathrm{e}}=p=s=s^{\mathrm{e}}$, which then yields the inflation bias of discretionary monetary policy:

$$
m=\psi=\frac{\Omega \alpha \varepsilon \eta[\lambda(\alpha+\varepsilon-\alpha \varepsilon)+\varepsilon] K}{b\left\{\eta(\alpha+\varepsilon-\alpha \varepsilon)[\lambda(\alpha+\varepsilon-\alpha \varepsilon)+\varepsilon]-\alpha\left(\eta-\varepsilon \beta^{2}\right)[\lambda(\alpha+\varepsilon-\alpha \varepsilon)+\Omega \varepsilon]\right\}} .
$$

As in standard time-inconsistency models of the Barro-Gordon variety, a decrease in $b$, the weight that the monetary authority places on inflation in the loss function, boosts the inflation bias. So does an increase in $K$, the wedge between full-information output and the monetary authority's target output level.

In an open economy with imperfectly competitive firms, the inflation bias also depends on other factors, including the amount of economy-wide wage rigidity, the elasticity of expenditures with respect to the real exchange rate, the degree of openness, and the extent of product substitutability. An increase in economy-wide wage rigidity resulting from an increase in the portion of sectors with contracts, $\Omega$ magnifies the scope of the time-inconsistency problem and thereby pushes up the inflation bias. Naturally, if there are no sectors with wage contracts, so that $\Omega=0$, the time-inconsistency problem disappears, and $\psi=O$.

The effect of an increase in the real-exchange-rate elasticity on the inflation bias is given by

$$
\frac{\partial \psi}{\partial \eta}=\frac{\alpha \varepsilon^{2} \beta^{2} \Omega K(\Omega \varepsilon+\gamma \lambda)(\gamma \lambda+\varepsilon)}{b\left[\eta \gamma(\lambda \gamma+\varepsilon)-\alpha\left(\eta-\varepsilon \beta^{2}\right)(\lambda \gamma+\Omega \varepsilon)\right]^{2}}>0 .
$$

If the sensitivity of desired domestic spending with respect to the real exchange rate increases, then variations in the terms-of-trade have larger effects on output. This gives the monetary authority a greater incentive to boost the domestic money stock in order to bring about a real depreciation of the domestic currency. Thus, a higher value of $\eta$ increases the inflation bias, ceteris paribus, even though a rise in $\eta$ reduces the sacrifice ratio.

Both the degree of openness and the extent of product substitutability also affect the inflation bias. It follows directly from Eq. (13) that $(\partial \psi / \partial \beta)<0$ is the relevant outcome for a typical open economy. Consequently, increased openness tends to reduce the inflationary bias of discretionary monetary policy, which is consistent with the empirical evidence. As noted 
earlier, it is theoretically feasible for the output-inflation trade-off to slope downward for sufficiently small values of $\varepsilon$. This contributes to the potential for the inflation bias to respond ambiguously to an increase in the extent of substitutability of products. For the relatively larger range of values of $\varepsilon$ consistent with an upward-sloping output-inflation trade-off, however, it is straight-forward to show that a higher value of $\varepsilon$ reduces the inflation bias. In general, both greater product substitutability and increased openness diminish the pricing power of domestic firms and thereby reduce the degree to which a given monetary expansion can raise output via unexpected increases in the domestic price level.

\section{Conclusion}

The upshot of our analysis is the prediction that greater openness increases the sacrifice ratio while reducing the inflationary bias of discretionary monetary policy in an imperfectly competitive open economy in which nominal wages are set in advance of price and output determination in some sectors but not in others. Thus, observation of a positive correlation between openness and the sacrifice ratio even in the presence of an inverse relationship between openness and mean inflation is consistent with the results of our analysis.

Temple's contribution raises important questions about the relationship between the sacrifice ratio and mean inflation. Our analysis implies that his findings could result in part from cross-country differences in the extent of wage rigidity, in the degree of product substitutability, and in the sensitivity of aggregate expenditures with respect to the real exchange rate. Work by Ghosal and Loungani $(1996)$ and Duca and VanHoose $(1998,2001)$ indicates that a multisector environment in which only a portion of firms negotiate nominal wage contracts may be relevant in the United States. For the United States and certain other nations that may fit this mold, our model predicts that there is more likely to be a positive observed relationship between openness and the measured sacrifice ratio, even though increased openness leads to a lower inflation bias. This result would be strengthened if we were to follow Karras (1999) by including the potential for indexation of wages to the consumer price index, although in our imperfectcompetition framework this would introduce a source of potential ambiguity concerning the theoretical effect of openness on trend inflation.

In other countries, a combination of significant international interdependence (a relatively low value of $\eta$ in our model), extensive substitutability among products (a relatively large value of $\varepsilon$ ), and considerable economy-wide wage rigidity (a value of $\Omega$ relatively near unity) would tend to make the standard Barro-Gordon model more applicable. In our model, creating a 
negative relationship between openness and the sacrifice ratio in the case in which $\eta \rightarrow 0, \varepsilon \rightarrow$ $\infty$, and $\Omega \rightarrow 1$ requires including other international linkages not incorporated into the structural framework. Romer (1993), for instance, highlights ways in which openness might increase the responsiveness of domestic firms' input costs to changes in the consumer price index, thereby reducing the sacrifice ratio within a purely competitive setting.

These considerations imply that empirical tests using cross-country or pooled international data to evaluate the implications of increased openness for sacrifice ratios, trend inflation, or other macroeconomic policy variables could be subject to misspecification problems. The effects of openness on both the slope of a nation's output-inflation trade-off and the responsiveness of its price level to monetary expansions can depend crucially on structural factors. For instance, our analysis identifies the real-exchange-rate sensitivity of its aggregate expenditures, the competitive structure of its product markets, and the nature of its labor-market arrangements-which are just a subset of structural factors highlighted as potentially important in the new open economy macroeconomics literature.

Consistent with the implications of the new open economy macroeconomics literature, our analysis indicates the potential for pitfalls in otherwise very carefully done empirical work that nonetheless does not take into account important structural differences across economies. For instance, cross-country comparisons or panel studies using pooled country data could yield results about the interactions among, openness, the sacrifice ratio, and trend inflation that are difficult to interpret in the absence of efforts to control for structural differences among nations. Daniels et al. (2005), for instance, demonstrate that controlling for just one other structural factor in cross-country data-namely, central bank independence-is sufficient to uncover the positive relationship between openness and the sacrifice ratio predicted by our model.

Our conclusion, therefore, is that failure to find apparent evidence of a negative relationship between the sacrifice ratio and mean inflation does not necessarily cast doubt on the relevance s of the time-inconsistency approach as an explanation for the openness-inflation relationship. Although our analysis and preceding work uniformly indicate that increased openness should reduce mean inflation, our results imply that how openness and the sacrifice ratio interact depends fundamentally on the structures of nations' goods and labor markets. Future empirical work should extend the work of Temple and Karras by focusing on the potential roles of various structural factors, such as national differences in the extent of aggregate wage rigidity, the scope of product substitutability, the real-exchange-rate sensitivity of domestic spending, the degree of central bank independence, and, based on Gruben and McLeod (2002,

\section{Daniels \& VanHoose}


2004), the extent of capital market liberalization. In open economies with imperfectly competitive product markets, all of these factors are likely to influence the relationship among openness, the sacrifice ratio, and inflation.

\section{Notes}

- ${ }^{a}$ Department of Economics, College of Business Administration, Marquette University, Straz Hall, P.O. Box 1881, Milwaukee, WI 53201, USA

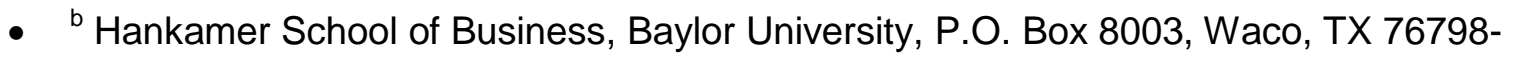
8003, USA

- * *Corresponding author. Tel.: +1 414288 3368; fax: +1 414288 5757. E-mail addresses: joseph.daniels@marquette.edu (J.P. Daniels), david_vanhoose@baylor.edu (D.D. VanHoose).

- ${ }^{1}$ Tel./fax: + 12547106206 .

\section{References}

Ball, L., 1994. What determines the sacrifice ratio? In: Mankiw, N.G. (Ed.), Monetary Policy. University of Chicago Press, Chicago, IL, pp. 155-193.

Ball, L., 1988. Is equilibrium indexation efficient? Quarterly Journal of Economics 103 (2), 299311.

Barro, R.J., Gordon, D.B., 1983. A positive theory of monetary policy in a natural rate model. Journal of Political Economy 91 (2), 589-610.

Bryson, J.H., Jensen, H., VanHoose, D.D., 1993. Rules, discretion, and international monetary and fiscal policy coordination. Open Economies Review 4 (2), 117-132.

Canzoneri, M.B., Henderson, D.W., 1991. Monetary Policy in Interdependent Economies: A Game Theoretic Approach. MIT Press, Cambridge, MA.

Daniels, J.P., Nourzad, F., VanHoose, D.D., 2005. Openness, central bank independence, and the sacrifice ratio. Journal of Money, Credit, and Banking 37 (2), 371-379.

Duca, J.V., VanHoose, D.D., 2000. Has greater competition restrained inflation? Southern Economic Journal 66 (3), 729-741.

Duca, J.V., VanHoose, D.D., 2001. The rise of goods-market competition and the fall of wage contracting: endogenous wage contracting in a multisector economy. Journal of Macroeconomics 23 (1), 1-29.

Duca, J.V., VanHoose, D.D., 1998. The rise of goods-market competition and the decline in wage indexation. Journal of Macroeconomics 20 (3), 579-598.

15 Daniels \& VanHoose 
Ghosal, V., Loungani, P., 1996. Evidence on nominal wage rigidity from a panel of U.S. manufacturing industries. Journal of Money, Credit, and Banking 28 (4), 650-668.

Gruben, W.C., McLeod, D., 2004. Capital market liberalization, disinflation, and commitment. Unpublished manuscript. Federal Reserve Bank of Dallas and Fordham University.

Gruben, W.C., McLeod, D., 2002. Capital account liberalization and inflation. Economics Letters $77,221-225$.

Hardouvelis, G., 1992. Monetary policy games, inflationary bias, and openness. Journal of Economic Dynamics and Control 16 (1), 147-164.

Karras, G., 1999. Openness and the effects of monetary policy. Journal of International Money and Finance 18 (1), 13-26.

Lane, P., 2001. The new open economy macroeconomics: a survey. Journal of International Economics 54 (2), 518-538.

Lane, P., 1997. Inflation in open economies. Journal of International Economics 42 (3/4), 327347.

Obstfeld, M., 2001. International macroeconomics: beyond the Mundell-Fleming model. IMF Staff Papers 47 (Special Issue), 1-39.

Rasmussen, B.S., 1993. Exchange Rate policy, union wage indexation, and credibility. Journal of International Economics 35 (1/2), 151-167.

Rogoff, K., 1985. Can international monetary policy cooperation be counterproductive? Journal of International Economics 18 (2), 198-217.

Romer, D., 1993. Openness and inflation: theory and evidence. Quarterly Journal of Economics 108 (4), 869-903.

Sarno, L., 2001. Towards a new paradigm in open economy modeling: where do we stand? Federal Reserve Bank of St. Louis Review 83 (3), 21-36.

Sarno, L., September 2000. Towards a new paradigm in open economy modeling: where do we stand? Manuscript, University of Warwick.

Temple, J., 2002. Openness, inflation, and the Phillips curve: a puzzle. Journal of Money, Credit, and Banking 34 (2), 450-468.

VanHoose, D.D., 2004. The new open economy macroeconomics: a critical appraisal. Open Economies Review 15 (2), 193-215. 